\title{
Evaluation of an Infection Control Measures Protocol Application by Nurses on Patients' Safety at Burn Units
}

\author{
Amany Ibrahim Ezz Eldeen ${ }^{1}$, Magda Abd-Elaziz², Amr Mohamed Moghazy ${ }^{3}$, Eman Saleh Shahin ${ }^{1}$, \\ Amal Bakr Abo El-Ata ${ }^{1}$ \\ ${ }^{1}$ Medical Surgical Nursing Department, Faculty of Nursing, Port Said University, Port-Said, Egypt \\ ${ }^{2}$ Medical Surgical Nursing, Faculty of Nursing, Ain Shams University, Cairo, Egypt \\ ${ }^{3}$ Plastic Surgery \& Emergency Medicine Department, Faculty of Medicine, Suez Canal University, Ismailia, Egypt
}

Email address:

amanyez2002@yahoo.com (A. I. Ezz. Eldeen),moghazy@yahoo.com (A. M. Moghazy), eman.shahin@nur.psu.edu.eg (E. S. Shahin), amelsarwat@yahoo.com (A. B. Abo El-Ata)

\section{To cite this article:}

Amany Ibrahim Ezz Eldeen, Magda Abd-Elaziz, Amr Mohamed Moghazy, Eman Saleh Shahin, Amal Bakr Abo El-Ata. Evaluation of an Infection Control Measures Protocol Application by Nurses on Patients' Safety at Burn Units. Journal of Surgery. Special Issue: Surgical Infections and Sepsis. Vol. 4, No. 3-1, 2016, pp. 1-9. doi: 10.11648/j.js.s.2016040301.11

Received: January 28, 2016; Accepted: January 29, 2016; Published: March 23, 2016

\begin{abstract}
Introduction: Healthcare-Associated Infection (HAI) has become a major component of the national and international movement to enhance patient safety. Infection is the most common cause of death among burn patients following the burn injury itself. Nurses are at the center of patient care and are the healthcare professionals most likely to intercept errors and prevent harm to patients. The aim of this study was to improve nurses' performance in Burn Units regarding infection control measures with subsequent enhancement of the patients' safety. Subjects and methods: The data were collected using three tools: a self-administered questionnaire, an observation checklist, and a bacteriological culture results form. The results of this study indicated that the percentage of nurses having satisfactory knowledge increased from a pre-intervention level of $17.6 \%$, to a post intervention level of $67.6 \%$. This improvement was statistically significant $(p<0.001)$; as well the percentage of nurses having adequate practice rose from a pre-intervention level of $0.0 \%$, to a post intervention level of $85.3 \%$, with statistically significant difference $(\mathrm{p}<0.001)$. There were no any statistically significant correlations between nurses' knowledge and practice scores before and after the intervention. Moreover, the number of nurses with negative hands' culture results increased from 3(8.8\%) to $7(20.6 \%)$, but the difference was not statistically significant. The intervention program was identified as the main positive predictor of the change in nurses' knowledge and practice scores. In conclusion, nurses' knowledge of infection control in burn units and their related practice are very deficient; the educational intervention is successful in improving them. The intervention is also successful in decreasing the Bacillus spp. in nurses' culture samples. The study recommended different strategies to decrease rates of infection as well as improve patient safety.
\end{abstract}

Keywords: Infection Control, Protocol, Nurses, Burn Unit

\section{Introduction}

In nursing, the concept of safety is fundamental to the care of clients and the safety of care providers [1]. Meanwhile, patient safety practices have been defined as "those that reduce the risk of adverse events related to exposure to medical care across a range of diagnoses or conditions [2].

Healthcare-Associated Infection (HAI) has become a major component of the national and international movement to enhance patient safety $[3,4]$. Moreover, the Institute of
Medicine report recommended immediate and strong mandatory reporting of other adverse health events, suggesting that public monitoring may hold healthcare facilities more accountable to improve the quality of medical care and to reduce the incidence of infections [5].

Infection is the most common cause of death among burn patients following the burn injury itself [6]. Thus, the burn care units can be the site of explosive and prolonged outbreaks caused by resistant organisms [7]. The organisms associated with infection in burn patients include gram- 
positive, gram-negative, and yeast/fungal organisms. The distribution of organisms changes over time in the individual patient and such changes can be ameliorated with appropriate management of the burn wound and patient [8]. The sources of these organisms include the patient's own endogenous (normal) flora, exogenous sources in the environment, and from healthcare personnel $[9,10]$.

Prevention of HAI has become a major patient safety initiative [11]. Infection prevention and control refers to measures, practices, protocols and procedures aimed at preventing and controlling infections and transmission of infections in health care settings [12]. Any laxity in the application of infection control measures can result in significant negative consequences [13].

Infection risk is significantly increased as patient care equipment becomes more and as more devices that disrupt naturally protective anatomic barriers are used [13]. Nurses are at the center of patient care and are the healthcare professionals most likely to intercept errors and prevent harm to patients. They can directly prevent infections by performing, monitoring, and assuring compliance with aseptic work practices; providing knowledgeable collaborative oversight on environmental decontamination; serve as the primary resource to identify and refer ill visitors or staff; reduce the risk for infection and colonization using evidence-based aseptic work practices [9]. Hence, nurses should receive additional infection control training and periodic evaluations of aseptic care as a planned patient safety activity [14]. This is of particular importance in burn units [4].

The aim of this study was to improve nurses' performance in the Burn Units regarding infection control measures with subsequent enhancement of the patient's safety.

Objectives:

1. Assess nurses' knowledge and practice about infection control in Burn Unit.

2. Develop a protocol for nurses, from the already available studies, about infection control measures in Burn Unit.

3. Implement the protocol based on actual needs of nurses in this sitting.

4. Evaluate the impact of implemented protocol on performance of nurses regarding infection control and the incidence of nosocomial infection in Burn Unit.

\section{Subjects and Methods}

\subsection{Research Design and Setting}

A quasi-experimental research design with pre-post assessment was used in this study, which was carried out in the burn units of Ismailia University Hospital, Mansoura University Hospital, and Port-Said General Hospital.

\subsection{Subjects}

The study subjects consisted of all the nurses working in the aforementioned hospitals during the time of the study, except those under training and student nurses at any educational level. Their number (34) constituted a sample size large enough to detect an improvement in nurses' knowledge or practice score from a $30 \%$ level before the intervention to $75 \%$ after the intervention at $95 \%$ level of confidence, $80 \%$ power, and accounting for approximately $20 \%$ dropout.

\subsection{Data Collection Tools}

A self-administered questionnaire and an observation checklist were used in data collection, in addition to a bacteriological culture results form. The self-administered questionnaire was developed by the researcher to assess nurses' knowledge related to infection control before and after the intervention. It included questions about socio-demographic and work characteristics, and 123 questions in various forms (72 true/false questions, 34 completion questions, and 17 multiple-choice questions) covering various areas of HAI and infection control. For each of the knowledge questions, a correct response was scored "One" and the incorrect "Zero." For each area of knowledge, the scores of its questions were summed-up and the total divided by the number of questions, and converted into percent scores. Nurse's knowledge was considered "satisfactory" if the percent score was $60 \%$ or higher and "unsatisfactory" if less than $60 \%$.

The nurse's observation checklist was developed by the researcher to assess nurse's practice of infection control procedures. It included seven checklists covering various aspects of the infection control measures. These were hand washing (21 items), donning and removing sterile gloves (23 items), donning and removing masks (9 items), donning and removing sterile gown (13 items), taking body temperature ( 5 items), vein puncture and insertion of peripheral IV lines (27 items), and wound dressing (41 items) checklists. Each item was checked as "done," "not done," or "not applicable." The items observed as "done" were scored "1" and the items "not done" were scored "0." The items checked "not applicable" were not given any points and their scores were discounted from the total. For each checklist, the scores of the items were summed-up and the total divided by the number of items, and converted into percent scores. The nurse's practice was considered "adequate" if the percent score was $60 \%$ or more and "inadequate" if less than $60 \%$.

Bacteriological culture form: The researcher used this sheet to document the laboratory findings of the culture of the nurses' hands. Upon development of the data collection tools, their preliminary form was presented to a jury group for validation. The group consisted of ten medical and nursing experts in infection control and in medical-surgical nursing. Their opinions were sought regarding the form, content, comprehensiveness, sequence, clarity, and applicability of the data collection tools for face and content validation. The tools were modified based on their comments and suggestions and then pilot-tested.

\subsection{Fieldwork}

The work was conducted through assessment, planning, 
implementation, and evaluation phases.

1. Assessment phase: After finalization of the tools in the pilot study, the researcher started to identify and recruit the nurses. Nurse's knowledge and performance related to infection control were assessed using their selfadministered questionnaire and observation checklist. The obtained data composed the pretest results as a baseline before the intervention. For assessment of bacterial contamination, swabs were taken from nurses' hands and sent for bacteriological culture and the results provided pretest data.

2. Planning phase: Bawd on the information obtained in the nurses' pretest and in view of related literature, the researcher designed the educational program. Its main goals were to improve nurses' knowledge and performance regarding infection control measures in the Burn Units, and promote safety among patients in these units. The researcher prepared an illustrated booklet to foster nurses' benefits from the intervention. The program was divided in sessions. The content of the sessions covered the theoretical and practical aspects of nosocomial infections. The main areas of knowledge were related to definitions of nosocomial infection and universal precautions, infection control procedures, hand hygiene, personal protective equipment (PPE), vaccination, safe waste disposal, dealing with sharps, general precautions, wound infection etiology, transmission, urinary tract infections, sterilization, and care of cannula. The practical part of the program covered training in the performance of various skills related to infection control measures. They included hand washing, donning and removing sterile gloves, masks, sterile gown, measuring body temperature, vein puncture and insertion of peripheral IV lines, and wound dressing.

3. Implementation phase: The program was implemented to participating nurses in small group session. Four sessions were delivered monthly, and every session was repeated twice weekly in each setting for a period of 6 months. The duration of the session ranged between 30 and 45 minutes. The researcher used selected adult teaching methods as role-playing and discussion, as well as teaching media as films, videos, data-show and brochures. Some resources and supplies were provided by the researcher to nurses such as alcohol rub gel and paper towels to facilitate the implementation of the program.

4. Evaluation phase: The program outcome was evaluated by comparing the results of the pre and post-tests using the same data collection forms.

\subsection{Limitations of the Study}

Some of participants refused to participate in the study because they were worried about reporting their data to their workplace despite the reassurance given by the researcher. The lack of supplies and facilities at the follow-up could have negatively affected the impact of the intervention since the researcher made these supplies available to them at her own expenses during the training but not during follow-up due to the high costs.

\subsection{Administrative and Ethical Considerations}

Official permissions to conduct the study were obtained from the heads of the burn units of the concerned hospitals. The study protocol was approved by the Research and Ethics committee at the Faculty of Nursing, Port-Said University. An informed oral consent was obtained by each nurse after explaining the study aim and procedures. Participants were informed about their right to withdraw from the study at any time without giving any reason. Data were considered confidential and not be used outside this study.

\subsection{Statistical Analysis}

Data entry and statistical analysis were done using SPSS 20.0 statistical software package. Qualitative categorical variables were compared using chi-square test. Whenever the expected values in one or more of cell in a $2 \times 2$ tables was less than 5, Fisher exact test was used instead. In larger than $2 \times 2$ cross-tables, no test could be applied whenever the expected value in $10 \%$ or more of the cells was less than 5 . Spearman rank correlation was used for assessment of the inter-relationships among quantitative variables and ranked ones. In order to identify the independent predictors of nurses' knowledge and practice scores, multiple linear regression analysis was used after testing for normality, and homoscedasticity and analysis of variance for the full regression models were done. Statistical significance was considered at $\mathrm{p}$-value $<0.05$.

\section{Results}

The study sample consisted of 34 nurses aged 18 to 50 years, with a majority being females $(94.1 \%)$ and married $(82.4 \%)$ as shown in Table 1. Almost all study nurses were having diploma degrees, except only $1(2.9 \%)$ having a bachelor degree. Slightly more than one-half of them (52.9\%) were having ten or more years of experience in nursing, but less than ten years of experience in burn units. Slightly less than half $(47.1 \%)$ of the nurses had previously attended training courses in infection control, and $11.8 \%$ had previously worked in hospitals having infection control units.

Nurses' knowledge of infection control in burn units before and after the intervention was traced in table 2 which demonstrated, statistically significant improvements at the post-intervention test in almost all areas of knowledge.

Table 3 points to very low percentages of nurses' pre intervention adequate practices. Only $1(2.9 \%)$ nurse showed adequate practice of hand washing, wearing mask, and vein puncture. Meanwhile, $88.2 \%$ of the nurses had adequate practice before wound dressing. At the post-intervention phase, the percentages of adequate practice increased in all areas, reaching $100 \%$ in five practices.

Concerning the results of nurses' hands culture for 
microorganisms, Table 4 demonstrated that the number of nurses with negative culture results increased from $8.8 \%$ to $20.6 \%$, but the difference was not statistically significant.

Table 5 demonstrates the absence of any statistically significant correlations between nurses' knowledge and practice scores before and after the intervention. Meanwhile, nurses' age correlated negatively with their pre-intervention knowledge $(r=-0.376)$. Moreover, their experience years correlated negatively with their knowledge at both study phases.

Table 1. Socio-demographic and job characteristics of nurses in the study sample $(n=34)$.

\begin{tabular}{|c|c|c|}
\hline & Frequency & Percent \\
\hline \multicolumn{3}{|l|}{ Age: } \\
\hline$<30$ & 19 & 55.9 \\
\hline $30+$ & 15 & 44.1 \\
\hline Range & $18.0-50.0$ & \\
\hline Mean \pm SD & $30.9 \pm 9.6$ & \\
\hline Median & 27.00 & \\
\hline \multicolumn{3}{|l|}{ Gender: } \\
\hline Male & 2 & 5.9 \\
\hline Female & 32 & 94.1 \\
\hline \multicolumn{3}{|l|}{ Nursing qualification: } \\
\hline Secondary nursing diploma & 29 & 85.3 \\
\hline Specialty diploma & 1 & 2.9 \\
\hline Technical institute & 3 & 8.8 \\
\hline Bachelor & 1 & 2.9 \\
\hline \multicolumn{3}{|l|}{ Marital status: } \\
\hline Married & 28 & 82.4 \\
\hline Single & 6 & 17.6 \\
\hline \multicolumn{3}{|l|}{ Experience years (total): } \\
\hline$<10$ & 16 & 47.1 \\
\hline $10+$ & 18 & 52.9 \\
\hline Range & $1.0-32.0$ & \\
\hline Mean \pm SD & $9.5 \pm 0.5$ & \\
\hline Median & 10.00 & \\
\hline \multicolumn{3}{|l|}{ Experience years (burns unit): } \\
\hline$<10$ & 18 & 52.9 \\
\hline $10+$ & 16 & 47.1 \\
\hline Range & $0.0-29.0$ & \\
\hline Mean \pm SD & $11.0 \pm 8.1$ & \\
\hline Median & 8.50 & \\
\hline Attended training in infection control & 16 & 47.1 \\
\hline Previously worked in hospitals having infection control units & 4 & 11.8 \\
\hline
\end{tabular}

Table 2. Nurses' knowledge before and after the intervention.

\begin{tabular}{|c|c|c|c|c|c|c|}
\hline \multirow{3}{*}{ Satisfactory Knowledge $(60 \%+)$} & \multicolumn{4}{|c|}{ Time } & \multirow{3}{*}{$\mathrm{X}^{2}$ test } & \multirow{3}{*}{ p-value } \\
\hline & \multicolumn{2}{|c|}{ Pre } & \multicolumn{2}{|l|}{ Post } & & \\
\hline & No. & $\%$ & No. & $\%$ & & \\
\hline Nosocomial infection & 11 & 32.4 & 30 & 88.2 & 22.18 & $<0.001 *$ \\
\hline Universal precautions & 8 & 23.5 & 20 & 58.8 & 8.74 & $0.003^{*}$ \\
\hline Infection control procedures & 19 & 55.9 & 25 & 73.5 & 2.32 & 0.13 \\
\hline Hand hygiene & 18 & 52.9 & 33 & 97.1 & 17.65 & $<0.001 *$ \\
\hline Personal protective equipment (PPE) & 16 & 47.1 & 29 & 85.3 & 11.10 & $0.001 *$ \\
\hline Vaccination & 13 & 38.2 & 21 & 61.8 & 3.76 & 0.052 \\
\hline Safe waste disposal & 10 & 29.4 & 31 & 91.2 & 27.09 & $<0.001 *$ \\
\hline Dealing with sharps & 15 & 44.1 & 31 & 91.2 & 17.20 & $<0.001 *$ \\
\hline General precautions & 14 & 41.2 & 27 & 79.4 & 10.38 & $0.001 *$ \\
\hline Wound infection & 2 & 5.9 & 22 & 64.7 & 25.76 & $<0.001 *$ \\
\hline Etiology & 4 & 11.8 & 10 & 29.4 & 3.24 & 0.07 \\
\hline Transmission & 2 & 5.9 & 9 & 26.5 & 5.31 & $0.02 *$ \\
\hline Urinary tract infections & 5 & 14.7 & 12 & 35.3 & 3.84 & 0.050 \\
\hline Sterilization & 11 & 32.4 & 32 & 94.1 & 27.90 & $<0.001 *$ \\
\hline Care of cannula & 4 & 11.8 & 28 & 82.4 & 34.00 & $<0.001 *$ \\
\hline \multicolumn{7}{|l|}{ Total knowledge: } \\
\hline Satisfactory & 6 & 17.6 & 23 & 67.6 & & \\
\hline Unsatisfactory & 28 & 82.4 & 11 & 32.4 & 17.38 & $<0.001 *$ \\
\hline
\end{tabular}

(*) Statistically significant at $\mathrm{p}<0.05$. 
Table 3. Nurses' practice before and after the intervention.

\begin{tabular}{|c|c|c|c|c|c|c|}
\hline \multirow{3}{*}{ Adequate practice $(60 \%+):{ }^{a}$} & \multicolumn{4}{|c|}{ Time } & \multirow{3}{*}{$X^{2}$ test } & \multirow{3}{*}{ p-value } \\
\hline & \multicolumn{2}{|c|}{ Pre } & \multicolumn{2}{|c|}{ Post } & & \\
\hline & No. & $\%$ & No. & $\%$ & & \\
\hline Hand washing & 1 & 2.9 & 10 & 29.4 & 8.78 & $0.003 *$ \\
\hline \multicolumn{7}{|l|}{ Gloving: } \\
\hline Wearing & 0 & 0.0 & 24 & 70.6 & 37.09 & $<0.001 *$ \\
\hline Removing & 0 & 0.0 & 32 & 94.1 & 60.44 & $<0.001 *$ \\
\hline Total gloving & 0 & 0.0 & 30 & 88.2 & 53.68 & $<0.001 *$ \\
\hline \multicolumn{7}{|l|}{ Masking: } \\
\hline Wearing & 1 & 2.9 & 33 & 97.1 & 60.24 & $<0.001 *$ \\
\hline Removing & 0 & 0.0 & 33 & 97.1 & 64.11 & $<0.001 *$ \\
\hline Total masking & 0 & 0.0 & 33 & 97.1 & 64.11 & $<0.001 *$ \\
\hline \multicolumn{7}{|l|}{ Gowning: } \\
\hline Wearing & 0 & 0.0 & 31 & 100.0 & 63.00 & $<0.001 *$ \\
\hline Removing & 0 & 0.0 & 31 & 100.0 & 63.00 & $<0.001 *$ \\
\hline Total gowning & 0 & 0.0 & 31 & 100.0 & 63.00 & $<0.001 *$ \\
\hline Taking body temperature & 0 & 0.0 & 34 & 100.0 & 68.00 & $<0.001 *$ \\
\hline Vein puncture & 1 & 2.9 & 28 & 82.4 & 43.83 & $<0.001 *$ \\
\hline \multicolumn{7}{|l|}{ Wound dressing: } \\
\hline Before & 30 & 88.2 & 34 & 100.0 & Fisher & 0.11 \\
\hline During & 0 & 0.0 & 22 & 64.7 & 32.52 & $<0.001 *$ \\
\hline After & 0 & 0.0 & 6 & 17.6 & Fisher & 0.02 \\
\hline Total wound dressing & 0 & 0.0 & 25 & 73.5 & 39.53 & $<0.001 *$ \\
\hline \multicolumn{7}{|l|}{ Total practice: } \\
\hline Adequate & 0 & 0.0 & 29 & 85.3 & & \\
\hline Inadequate & 34 & 100.0 & 5 & 14.7 & 50.56 & $<0.001 *$ \\
\hline
\end{tabular}

(*) Statistically significant at $\mathrm{p}<0.05$

(@) Excluding the not applicable

Table 4. Nurses' hands' culture results before and after the intervention.

\begin{tabular}{|c|c|c|c|c|c|c|}
\hline & \multicolumn{4}{|c|}{ Time } & \multirow{3}{*}{$X^{2}$ test } & \multirow{3}{*}{ p-value } \\
\hline & \multicolumn{2}{|c|}{ Pre } & \multicolumn{2}{|l|}{ Post } & & \\
\hline & No. & $\%$ & No. & $\%$ & & \\
\hline \multicolumn{7}{|l|}{ Culture: } \\
\hline Gram -ve & 20 & 58.8 & 23 & 67.6 & & \\
\hline Gram +ve & 2 & 5.9 & 2 & 5.9 & -- & -- \\
\hline Both & 9 & 26.5 & 2 & 5.9 & & \\
\hline None & 3 & 8.8 & 7 & 20.6 & & \\
\hline \multicolumn{7}{|l|}{ Culture: } \\
\hline Negative & 3 & 8.8 & 7 & 20.6 & & \\
\hline Positive & 31 & 91.2 & 27 & 79.4 & 1.88 & 0.17 \\
\hline \multicolumn{7}{|c|}{ Gram-ve organisms: ${ }^{@}$} \\
\hline E. coli & 10 & 50.0 & 3 & 13.0 & & \\
\hline Klebsiella & 8 & 40.0 & 5 & 21.7 & & \\
\hline Pseudomonous & 14 & 70.0 & 14 & 60.9 & & \\
\hline Actinobacter & 15 & 75.0 & 2 & 8.7 & -- & -- \\
\hline Enterobacter & 7 & 35.0 & 2 & 8.7 & & \\
\hline MRSA & 1 & 5.0 & 1 & 4.3 & & \\
\hline Proteus & 2 & 10.0 & 2 & 8.7 & & \\
\hline \multicolumn{7}{|c|}{ Gram +ve organisms: ${ }^{@}$} \\
\hline Staph aureus & 0 & 0.0 & 3 & 75.0 & -- & -- \\
\hline Bacillus spp & 6 & 100.0 & 1 & 25.0 & Fisher & $0.03 *$ \\
\hline Candida & 2 & 10.0 & 2 & 8.7 & -- & -- \\
\hline
\end{tabular}

(*) Statistically significant at $\mathrm{p}<0.05$

(--) Test result not valid

(@) Not mutually exclusive 
Table 5. Correlation between nurses'knowledge and practice scores and nurses'socio-demographic characteristics.

\begin{tabular}{|c|c|c|c|c|}
\hline & \multicolumn{4}{|c|}{ Spearman's rank correlation coefficient } \\
\hline & \multicolumn{2}{|c|}{ Pre } & \multicolumn{2}{|l|}{ Post } \\
\hline & Knowledge & Practice & Knowledge & Practice \\
\hline Practice & .202 & & .151 & \\
\hline Age & $-.376 *$ & -.073 & -.262 & -.196 \\
\hline Qualification & .117 & .075 & .104 & .287 \\
\hline Experience (total) & $-.391 *$ & -.074 & -.289 & -.194 \\
\hline Experience (burn unit) & $-.474 * *$ & -.174 & $-.349 *$ & -.209 \\
\hline
\end{tabular}

(*) Statistically significant at $\mathrm{p}<0.05$

(**) Statistically significant at $\mathrm{p}<0.01$

Table 6. Best fitting multiple linear regression model for the changes in nurses' knowledge and practice scores.

\begin{tabular}{|c|c|c|c|c|c|c|c|}
\hline & \multicolumn{2}{|c|}{ Unstandardized Coefficients } & \multirow{2}{*}{$\begin{array}{l}\text { Standardized } \\
\text { Coefficients }\end{array}$} & \multirow{2}{*}{ t-test } & \multirow{2}{*}{ p-value } & \multicolumn{2}{|c|}{ 95\% Confidence Interval for B } \\
\hline & B & Std. Error & & & & Lower & Upper \\
\hline \multicolumn{8}{|l|}{ Knowledge } \\
\hline Constant & 48.46 & 10.82 & & 4.48 & $<0.001$ & 26.845 & 70.08 \\
\hline Hospital: Port-Said & 13.36 & 2.66 & .38 & 5.03 & $<0.001$ & 8.06 & 18.67 \\
\hline Age & -.79 & .22 & -.27 & 3.61 & .001 & -1.23 & -.35 \\
\hline Intervention & 34.80 & 4.15 & .64 & 8.40 & $<0.001$ & 26.52 & 43.08 \\
\hline \multicolumn{8}{|c|}{ r-square $=0.62$ Model ANOVA: $\mathrm{F}=36.63, \mathrm{p}<0.001$ Variables entered and excluded: gender, qualification, experience, training courses } \\
\hline \multicolumn{8}{|c|}{ Practice } \\
\hline Constant & -4.69 & 7.02 & & -.67 & .51 & -18.71 & 9.33 \\
\hline Female sex & -7.11 & 3.38 & -.07 & 2.10 & .04 & -13.85 & -.36 \\
\hline Intervention & 43.78 & 1.59 & .96 & 27.55 & $<0.001$ & 40.61 & 46.95 \\
\hline
\end{tabular}

In multivariate analysis (Table 6), the intervention program was identified as the main positive predictor of the change in nurses' knowledge score. Additionally, working in Port-Said Hospital was another positive predictor, whereas nurse's age was a negative predictor. The model explains $62 \%$ of the change in nurse's knowledge score. The same table presents the best fitting regression model for nurse's practice score. It demonstrates that the intervention program was the main positive predictor of the change in nurses' practice score. Conversely, nurse's female gender was a negative predictor. The model explains $92 \%$ of the change in nurse's practice score.

\section{Discussion}

The findings of the study generally indicate a positive impact on nurses' knowledge and to a less extent on their practice. The study involved a sample consisted of nurses with a wide age and experience range spanning over more than 30 years, which would increase the ability of generalization of the study findings.

According to the present study results, the nurses' knowledge of infection control in burn units was low at the pre-intervention phase of the study. This is extremely alarming finding could be attributed to the low level of nursing qualification in the majority of the sample. In agreement with these findings, a recent study in South Africa demonstrated that the health care providers' knowledge of healthcare-associated infections was deficient [15]. However, the implementation of the present study training intervention led to significant improvements in almost all areas of nurses' knowledge. A similar success of a training intervention in infection control for nurses was reported in a study in the United Kingdom [16]. Nonetheless, nurses' knowledge of the etiology of HAIs and urinary tract infection did not demonstrate statistically significant improvements. This might be explained by the difficulty of these two areas for the diploma degree nurses, which could be beyond their heads. In this respect, the competency in basic microbiology was one of the important areas of infection prevention and control specific to newly graduated nurses identified by consensus between expert panelists from Taiwan and Australia [17].

Overall, the present study findings revealed a success of the intervention training in improving nurses' knowledge of HAIs and infection control, which leads to acceptance of the first research hypothesis of the study. This success was confirmed by the results of multivariate analysis, which identified the intervention as the most influential significant independent predictor of the improvement in nurses' knowledge score. This success could be attributed to the content of the program, which responded to the needs of the nurses, as well as the simplicity of the language and of information, and the use of illustrated booklet. A similar success of training of nurses in infection control was reported by [18]; they reported statistically significant differences between the pre- and posttests' scores of nurses' total knowledge about infection control.

Other factors that influenced current study nurses' knowledge were the workplace, age, and experience years as revealed in the bivariate analyses. However, the multivariate analysis demonstrated that, in addition to the intervention, the 
work in Port-Said Hospital was a significant positive predictor of nurses' knowledge score, meaning more benefit for nurses from the intervention compared with the other two hospitals. This might be explained by their significantly higher levels of satisfactory knowledge at the preintervention phase. Similar variations in the nurses' knowledge and practice of ICMs was revealed in a study in Canada, and this was not only among hospitals but also among the units of the same hospital according to the nurses' perception of organizational support for safety [19]. The multivariate analysis also identified nurse's age as a significant independent negative predictor of the knowledge score, which might be explained by the higher enthusiasm, more eagerness to learn, and higher ability to assimilate new information among the younger age nurses. The lack of significant independent effect of experience on nurses' knowledge is in line with previous statements that stressed that the amount of knowledge required to take care of critically ill patients cannot be obtained simply through experience on the unit or at the bedside [20, 21].

The present study also revealed very deficient nurses' practices in all areas assessed. This alarming finding could have more than one explanation. The first is the lack of training of these nurses especially that the great majority of them are diploma degree nurses, and approximately one-half of them never attended training courses in infection control. The second is the lack of equipment and supplies required for application of infection control measures. The third is the lack of supervision and close monitoring of nurses' compliance to infection control measures. Similar explanations of nurses' deficient practice of ICMs have been previously reported [22, 23, 24].

After implementing the current study training intervention, statistically significant improvements were witnessed in nurses' practice in almost all areas. This improvement can be attributed to the effect of the intervention as confirmed by the results of the multivariate analysis, which identified the training intervention as the main significant independent positive predictor of the practice score. This leads to acceptance of the second research hypothesis concerning the improvement in nurses' practice of infection control measures. In congruence with these findings, significant improvements were reported in nurses' practice of ICMs in the Province of North Sumatera following training interventions [25, 26]. On the same line, [27] in a study in Egypt found a significant improvement in the total practice score of nurses regarding infection control after implementation of related training program. Additionally, the nurses' female gender was identified as a negative predictor of their practice score. This might be due to more eagerness to learn among male nurses in order to prove themselves in a profession that was mainly feminine until very recently. In agreement with this, a study in Germany reported that male nurses had significantly better practice of infection control measures compared with the female nurses [28].

The effectiveness of the present study intervention could have more than one underlying reason. Firstly, the program content and procedures was focused on applied knowledge with hands-on training. Secondly, the program followed the principles of adult learning, with student-centered, problembased approaches, with teaching strategies as discussion, and demonstration-re-demonstration. All nurses participated in the program had received a handout of the program content. Also, recurrent reinforcement for both knowledge and practice was done in each session. Thirdly, the researcher managed to make available the needed supplies and equipment during the time of the study. Fourthly, the researcher closely monitored nurses' practice during the training and provided immediate constructive feedback to participants. In agreement with this, a number of authors emphasized that successful educational programs are those that provide nurses with the necessary attitude and behavior skills basic to efficient practice of the work [29, 30, 31].

According to the present study findings, no significant correlations could be shown between nurses' knowledge and practice of infection control measures. This might be explained by the generally low scores of both in the preintervention phase. It may also reflect dissociation between the theoretical knowledge and the actual applied practice. Moreover, the practice does not depend only on knowledge, but it may also influence by other factors such as the availability of resources, supervision, organizational support, etc. Nonetheless, a similar study was shown in a recent study in Jordan, where no relations could be revealed between knowledge and practice [32].

The present study assessed the effectiveness of the intervention on infection control through nurses' knowledge and practice, and in addition used laboratory results as a more objective evidence of the improvement. The results of nurses' hands culture for microorganisms, showed a slight increase in the number of nurses with negative culture results, but the difference did not reach statistical significance. However, the decrease in the number of positive Bacillus spp. samples was statistically significant. This provides an objective evidence of the success of the training intervention in improving nurses' practice of infection control measures, which subsequently led to improvement in the lab results. This improvement in hand cultures may be attributed to that the researcher supplied the nurses with some extra resources such as paper towels and alcohol-rub gel, which has shown high effectiveness in hands' decontamination [33, 34].

Although the improvement in the results of the cultures from the hands of the nurses was not considerable in the present study, it is of major importance. In fact, the hands of the healthcare workers are among the most important sources of microorganisms for hospitalized patients in burn units [35]. Moreover, [5] stressed that effective hand hygiene can remove transient flora thus preventing cross-transmission of potentially harmful organisms and infection. Furthermore, a study in USA demonstrated that with the incorrect hand cleansing by healthcare workers during patient care, the level of hand contamination increased progressively in a linear fashion over time, thus favoring cross-transmission [36]. 


\section{Conclusion and Recommendations}

In conclusion, nurses' knowledge of infection control in burn units and their related practice are very deficient; the educational intervention is successful in improving them. The intervention is also successful in decreasing the Bacillus spp. in nurses' culture samples.

Based on the study results, it is recommended to apply the developed training module in the burns units of the study settings and in similar ones, encourage nurses to attend more training, and set a system for periodic evaluation of nurses' knowledge and practice in infection control. Making all supplies and equipment needed for application of infection control measures available to nurses is crucial.

\section{References}

[1] Treas LS, Wilkinson JM (2014): Basic nursing: concepts, skills, $\&$ reasoning. $1^{\text {st }}$ ed., Davis Company/ Philadelphia, USA, p. p. 604-683.

[2] Tourangeau AE, Cranley LA, Jeffs L Impact of nursing on hospital patient mortality: a focused review and related policy implications. Qual Saf Health Care (2006), 15(1): 48.

[3] Nguyen $Q V$ Hospital acquired infections. Emedicine. 2004. http://www.emedicine.com/PED/topic1619.htm. Internet accessed at March 2014.

[4] Saint S, Savel RH, Matthay MA Enhancing the safety of critically ill patients by reducing urinary and central venous catheter-related infections. Am J Respir Crit Care (2015) 165(1): 1475-1479.

[5] Jarvis WR (2014): Bennett and Brachman's hospital infections $6^{\text {th }}$ ed., Lippincott Williams \& Wilkins/ Philadelphia, USA, p. p. 1-752.

[6] Oncul E, Ulkur A, Acar L Prospective analysis of nosocomial infections in a burn care unit, Turkey. Indian Journal of Medical Research (2009), 130(6): 758-764.

[7] Coban $Y K$ Infection control in severely burned patients. World J Crit Care Med (2012), 1(4): 94-101.

[8] Azimi L, Motevallian A, Namvar AE, Asghari B, Lari AR Nosocomial Infections in Burned Patients in Motahari Hospital, Tehran, Iran. Dermatology Research and Practice (2011), Volume 2011 (2011), Article ID 436952, 4 pages. Available at Http://Dx.Doi.Org/10.1155/2011/436952. Internet accessed at March 2014.

[9] Hughes $R G$ Patient Safety and Quality: An Evidence-Based Handbook for Nurses: Agency for Healthcare Research and Quality, U. S. Department of Health and Human Services, 540 Gaither Road, 2008, Rockville, MD 20850. Internet accessed at February, 2014.

[10] Kacmarek RM, Stoller JM, Heuer AJ (2014): Fundamentals of Respiratory Care. $10^{\text {th }}$ ed., Elsevir/ Mosby, China, p. p. 62-81.

[11] The Research Committee of the Society of Healthcare Epidemiology of America. Enhancing Patient Safety by Reducing Healthcare-Associated Infections: The Role of Discovery and Dissemination. Infect Control Hosp Epidemiol (2010), 31(1) 118-123.
[12] The National Infection Prevention and Control Policy and Strategy, Republic of South Africa, 2007. pdf. Available at www.cddep.org/sites/.../prof adriano duse-1 0.pdf. Internet accessed at February 2014.

[13] Donegan NE (2014) Management of Patients with Infectious Diseases: Brunner \& Suddarth's Textbook of MedicalSurgical Nursing. $10^{\text {th }}$ ed., Mosby/Elsevier, New York, p.p. 2115-2122.

[14] Kinlay J, Flaherty K, Scanlon P, Mehrotra P Barriers to the use of face protection for standard precautions by health care providers. AJIC (2015), 43(2): 169-170.

[15] Dramowski A, Cotton MF, Rabie H, Whitelaw A Trends in paediatric bloodstream infections at a South African referral hospital. BMC Pediatrics (2015), 15(1): 33.

[16] Gilbert C1, Darlow B, Zin A, Sivasubramaniam S, Shah S, Gianini N, Beecroft $G$, Lopes Moreira ME Educating neonatal nurses in Brazil: a before-and-after study with interrupted time series analysis. Neonatology (2014), 106(3): 201-8.

[17] Liu LM, Curtis J, Crookes PA Identifying essential infection control competencies for newly graduated nurses: a threephase study in Australia and Taiwan. Journal of Hospital Infection (2014), 86 (2): 100-109.

[18] Ramya KR, Neethu $J$ Effectiveness of self instructional module on nursing management of patients with chest tube drainage for staff nurses working in a selected hospital of Odisha. International Journal of Nursing Education (2013) 5(2): 155-159.

[19] Rozenbojm $M D$, Nichol K, Spielmann S, Holness D Hospital unit safety climate: relationship with nurses' adherence to recommended use of facial protective equipment. Am J Infect Control (2015), 43(2): 115-20.

[20] The Institute of Medicine (IOM) Considers patient safety "indistinguishable from the delivery of quality health care. Romanian Journal of Bioethics (2010), 8(3): 149-159.

[21] Skees $J$ Continuing education, a bridge to excellence in critical care nursing. Crit Care Nurs Q (2010) 33(1): 104-116.

[22] Arranz P, Vlla S M, Ramos J L, Del-Rincon C, Lopez-Fando T Evaluation of a counseling training program for nursing staff. Patient-Edu. Couns (2007), 56 (2): 233-239.

[23] Barta SK, Stacy RD The effects of a theory-based training program on nurses' self-efficacy and behavior for smoking cessation counseling. J. Contin. Edu. Nurs (2007), 36(3): 117-123.

[24] Garfield R, Mccarthy $C F$ Nursing and nursing education in Iraq: challenges and opportunities. Int. Nurs. Rev (2008), 52 (3): 180-185.

[25] Elkadi JL (2007): health promotion regarding universal precaution HIV/AIDS for midwife of Primary Health Care in Medan municipality. Farmako No. 1, viewed 8/8/2008. Available at http://www.digilib.litbang.depkes.go.d/index.php. Internet accessed at October, 2014.

[26] Taha FA Impact of Universal Precautions Training on Nurse Midwives Knowledge, Attitude and Practices toward Prevention of HIV Transmission in Khartoum State. Teaching Hospitals, 2006-2009, Faculty of Nursing Sciences University of Khartoum. Available at www.davidpublishing.com/DownLoad/?id=16733. Internet accessed at November, 2014. 
[27] Ibrahim M. H. (2013): Effect of training program on nurses' performance regarding infection control in caring for patients with peripheral intervenous cannula. Doctorate Dissertation, Faculty of Nursing; Suez Canal University. Egypt.

[28] Mutters NT, Hagele U, Hagenfeld D, Hellwig E, Frank U Compliance with infection control practices in an university hospital dental clinic. GMS Hyg Infect Control (2014), 9(3): 18.

[29] Clinton M, Murrells T, Robinson S Assessing competency in nursing: A comparison of nurses prepared through degree and diploma programmes. J. Clin. Nurs (2006); 14(1): 82-94.

[30] Levett-Jones TL Continuing education for nurses: a necessity or a nicety? J Contin. Edu (2006), 36(5): 229-233.

[31] Jarrett $S L$, Hummel $F$, Whitney $K L$ Preparing for the $21^{\text {st }}$ century: graduate nursing education in Vietnam. Nurs. Edu. Perspect (2007), 26(3): 172-175.

[32] Al-Rawajfah OM, Tubaishat A Nursing students' knowledge and practices of standard precautions. A Jordanian web-based survey. Nurse Educ Today (2015), 6917(15) 00228-2.
[33] Sickbert-Bennett EE Comparative efficacy of hand hygiene agents in the reduction of bacteria and viruses. American Journal of Infection Control (2005), 33 (2): 67-77.

[34] Ozkurt Z, Altoparlak I, Yilmaz SI, Kemalettin SE Reducing hospital infection rates in the burn unit by adherence to infection control measures: a six-year experience. Turk J Med Sci (2012), 42 (1): 17-24.

[35] Anderson JL, Warren CA, Perez E, Louis RI, Phillips S, Wheeler J, Cole M, Misra $R$ Gender and ethnic differences in hand hygiene practices among college students. Am J Infect Control (2008), 36(5): 361-8.

[36] Tacconelli E, Cataldo MA, Dancer SJ, De Angelis G ESCMID guidelines for the management of the infection control measures to reduce transmission of multidrug-resistant Gramnegative bacteria in hospitalized patients. Clin Microbiol Infect (2014), 20 (1): 1-55. 